\title{
The trail to deadly membrane rafts
}

\author{
Florian Lang
}

Published online: 4 December 2012

(C) Springer-Verlag Berlin Heidelberg 2012

Tumor necrosis factor-related apoptosis inducing ligand (TRAIL) may stimulate death receptors (DR4 and DR5), decoy receptors (DcR1 and DcR2) antagonizing DR4 and DR5, and osteoprotegerin, a regulator of osteoclastogenesis and soluble TRAIL receptor [1]. All five receptors are expressed in endothelial cells and participate in the regulation of inflammation, proliferation, differentiation, and apoptosis [1]. Accordingly, TRAIL may stimulate or inhibit apoptosis. TRAIL-induced apoptosis involves activation of acid sphingomyelinase with subsequent generation of ceramide and formation of membrane signaling platforms via clustering of membrane rafts, outer cell membrane domains assembling cholesterol and lipids with saturated acyl chains, such as sphingolipids and glycosphingolipids [2]. Those platforms are particularly important for redox signaling, as they recruit several molecules decisive for $\mathrm{O}_{2}{ }^{-}$production, such as NADPH oxidase subunits, gp91 ${ }^{\text {phox }}$, $\mathrm{p} 47^{\text {phox }}$, and Rac GTPase [2].

In this issue, Li et al. [3] provide compelling evidence that in coronary arterial endothelial cells TRAIL leads to fusion of lysosomes with the cell membrane as well as formation of ceramide and ganglioside $\mathrm{G}_{\mathrm{M} 1}$-rich membrane rafts, which in turn provide redox signaling platforms for the stimulation of $\mathrm{O}_{2}^{-}$production. Oxidative stress is followed by endothelial injury and thus impairment of endothelium-dependent vasodilation.

\section{F. Lang $(\bowtie)$}

Department of Physiology, University of Tübingen,

Gmelinstr. 5,

72076 Tübingen, Germany

e-mail: florian.lang@uni-tuebingen.de
According to fluorescence imaging with specific lysosome probes, TRAIL-induced lysosome fusion with the cell membrane is blunted in gene-targeted mice lacking acid sphingomyelinase. Thus, acid sphingomyelinase is decisive for TRAIL-induced lysosomal trafficking and fusion with the cell membrane as well as formation of membrane raft redox signaling platforms. Lack of sphingomyelinase further prevents the impairment of endotheliumdependent vasodilation. TRAIL-induced membrane raft clustering has been observed in other cell types and is thus a general mechanism. Ceramide triggers the fusion of membrane raft microdomains to large ceramideenriched membrane domains (Fig. 1). Thus, ceramide plays an active role in membrane raft clustering [3].

Sphingomyelinase and ceramide are involved in the triggering of apoptosis following a wide variety of triggers including TRAIL, CD95, TNF-receptor, DR5, radiation, cytotoxic substances, bacteria, viruses, development, anti-CD20, and disruption of cellular contact with matrix molecules [4].

Sphingomyelinase is further decisive in the triggering of apoptosis by hyperosmotic shock [5], which leads to CD95 tyrosine phosphorylation, CD95 oligomerization, and trafficking of CD95 to the plasma membrane [5]. Osmotic cell shrinkage is followed by acidification of endosomal vesicles [6] with subsequent activation of vesicular acidic sphingomyelinase and ceramide formation [5]. Hyperosmotic shock further triggers the generation of reactive oxygen species (ROS) by NADPH oxidase, an effect again requiring ceramide [5]. Lysosomal acidification is required for ceramide formation and ROS generation, as they are both abrogated by inhibition of anion channels or of vacuolar-type $\mathrm{H}^{+}$ATPase [5]. ROS formation is followed by activation 


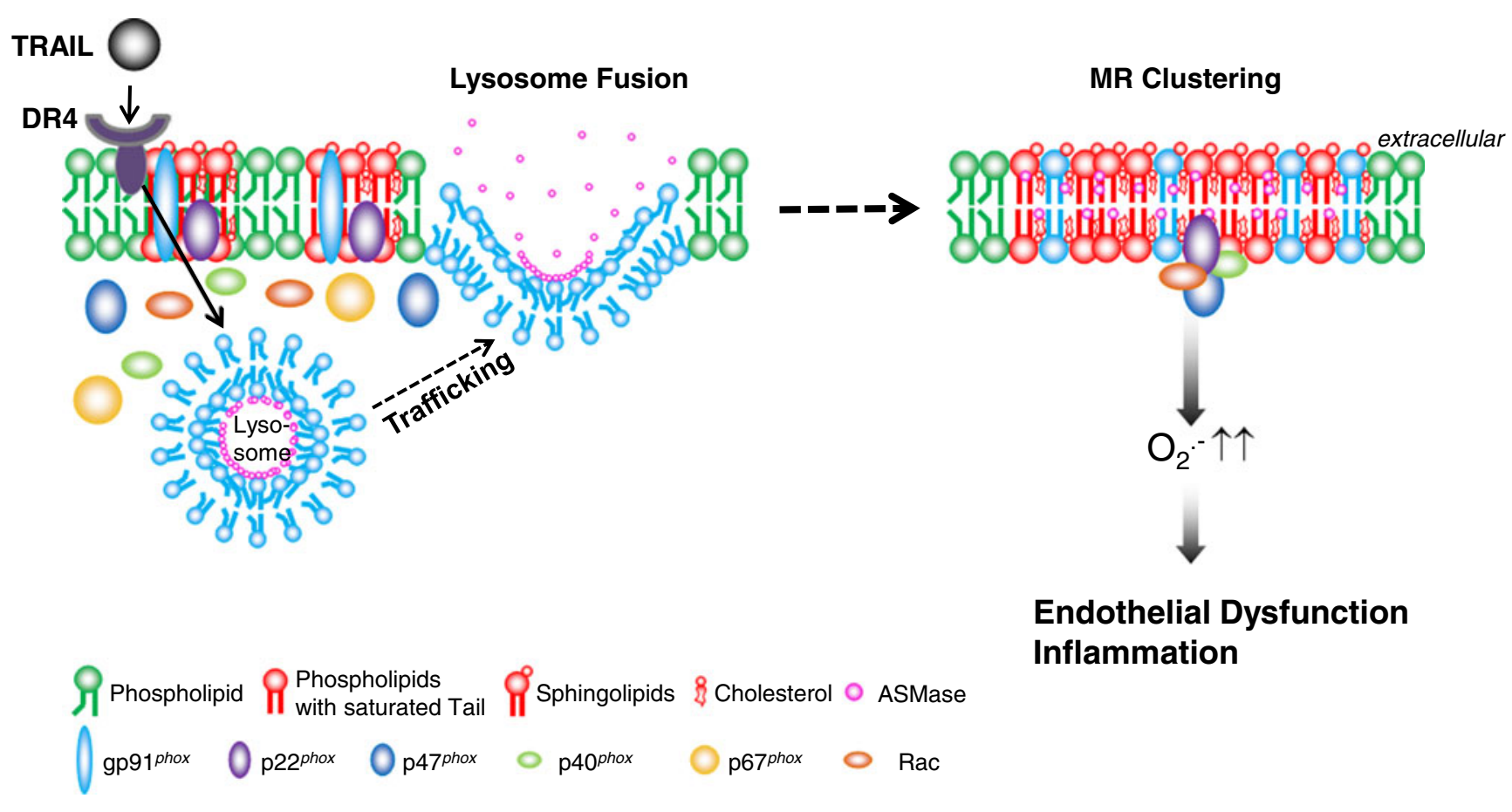

Fig. 1 Tentative model illustrating the hypothesis of Li et al. [3] (modified from Xia et al. [18])

of the tyrosine kinase Yes, which in turn leads to activation of the epidermal growth factor receptor (EGFR) [5]. EGFR-dependent activation of c-Jun-N-terminal kinase leads to association of CD95 with EGFR, to CD95 tyrosine phosphorylation by the EGFR tyrosine kinase, and to subsequent oligomerization and translocation of the CD95/EGFR complex to the plasma membrane with formation of the death inducing signaling complex eventually resulting in activation of caspase- 3 and caspase- $8[5,7]$.

Sphingomyelinase and ceramide are further involved in the triggering of suicidal erythrocyte death or eryptosis, which is characterized by cell membrane scrambling with subsequent exposure of phosphatdylserine at the erythrocyte surface [8]. Ceramide sensitizes the erythrocytes to the scrambling effect of cytosolic $\mathrm{Ca}^{2+}$ [8]. Acid sphingomyelinase and ceramide play a decisive role in the triggering of eryptosis during the course of several disorders, including sepsis, hemolytic uremic syndrome, and Wilson's disease [8]. Phosphatidylserine exposing suicidal erythrocytes adhere to endothelial CXCL16 [9], a scavenger receptor at the surface of inflammatory cells, which binds phosphatidylserine and oxidized low density lipoprotein. CXCL16 plays an important role in metastasis and atherosclerosis [9].
Sphingomyelinase does not only stimulate eryptosis but enhances the expression of endothelial CXCL16 [9].

The observations of Li et al. [3] are presumably of broad pathophysiological relevance. Besides their role in sepsis, hemolytic uremic syndrome, and Wilson's disease [8], sphingomyelinase and ceramide contribute to the pathophysiology of a wide variety of further clinical disorders including lung inflammation, fibrosis and infection [10], cystic fibrosis [11], several cardiovascular diseases [12, 13], multiple sclerosis [14], major depression [15], Parkinson's disease [16], Alzheimer's disease [15], and diabetes [17]. In all those conditions, lysosomal $\mathrm{pH}$, activity of acid sphingomyelinase, ceramide production with formation of membrane rafts, and subsequent $\mathrm{O}_{2}{ }^{-}$generation may contribute to the underlying pathophysiology.

The observations of $\mathrm{Li}$ et al. [3] shed light on a fundamental cellular mechanism. However, much is still to be learned about mechanisms regulating lysosomal $\mathrm{pH}$ and thus governing the activity of lysosomal acid sphingomyelinase and even more about the diverse pathophysiological ramifications of ceramide-enriched membrane rafts. It is hoped that the present flashlight encourages readers to engage in this exciting area of research. 


\section{References}

1. Holoch PA, Griffith TS (2009) TNF-related apoptosis-inducing ligand (TRAIL): a new path to anti-cancer therapies. Eur J Pharmacol 625:63-72

2. Jin S, Zhou F, Katirai F, Li PL (2011) Lipid raft redox signaling: molecular mechanisms in health and disease. Antioxid Redox Signal 15:1043-1083

3. Li X, Han W-Q, Boini K, Xia M, ZhangY, Li P-L (2012) TRAILdeath receptor 4 signaling via lysosome fusion and membrane raft clustering in coronary arterial endothelial cells: evidence from ASM knockout mice. J Mol Med. doi:10.1007/s00109-012-0968-y

4. Carpinteiro A, Dumitru C, Schenck M, Gulbins E (2008) Ceramide-induced cell death in malignant cells. Cancer Lett 264:1-10

5. Haussinger D, Reinehr R (2011) Osmotic regulation of bile acid transport, apoptosis and proliferation in rat liver. Cell Physiol Biochem 28:1089-1098

6. Lang F, Busch G, Volkl H, Haussinger D (1994) Lysosomal pH: a link between cell volume and metabolism. Biochem Soc Trans 22:502-505

7. Reinehr R, Haussinger D (2007) Hyperosmotic activation of the CD95 system. Methods Enzymol 428:145-160

8. Lang F, Gulbins E, Lang PA, Zappulla D, Foller M (2010) Ceramide in suicidal death of erythrocytes. Cell Physiol Biochem 26:21-28

9. Abed M, Towhid ST, Mia S, Pakladok T, Alesutan I, Borst O, Gawaz MP, Gulbins E, Lang F (2012) Sphingomyelinase-induced adhesion of eryptotic erythrocytes to endothelial cells. Am J Physiol Cell Physiol. doi:10.1007/s00109-012-0968-y
10. Dhami R, He X, Schuchman EH (2010) Acid sphingomyelinase deficiency attenuates bleomycin-induced lung inflammation and fibrosis in mice. Cell Physiol Biochem 26:749-760

11. Becker KA, Grassme H, Zhang Y, Gulbins E (2010) Ceramide in pseudomonas aeruginosa infections and cystic fibrosis. Cell Physiol Biochem 26:57-66

12. Kuebler WM, Yang Y, Samapati R, Uhlig S (2010) Vascular barrier regulation by $\mathrm{PAF}$, ceramide, caveolae, and $\mathrm{NO}$ - an intricate signaling network with discrepant effects in the pulmonary and systemic vasculature. Cell Physiol Biochem 26:29-40

13. Li X, Becker KA, Zhang Y (2010) Ceramide in redox signaling and cardiovascular diseases. Cell Physiol Biochem 26:41-48

14. Walter S, Fassbender K (2010) Spingolipids in multiple sclerosis. Cell Physiol Biochem 26:49-56

15. Kornhuber J, Tripal P, Reichel M, Muhle C, Rhein C, Muehlbacher M, Groemer TW, Gulbins E (2010) Functional inhibitors of acid sphingomyelinase (FIASMAs): a novel pharmacological group of drugs with broad clinical applications. Cell Physiol Biochem 26:9-20

16. Arboleda G, Huang TJ, Waters C, Verkhratsky A, Fernyhough P, Gibson RM (2007) Insulin-like growth factor-1-dependent maintenance of neuronal metabolism through the phosphatidylinositol 3-kinase-Akt pathway is inhibited by C2-ceramide in CAD cells. Eur J Neurosci 25:3030-3038

17. Holland WL, Summers SA (2008) Sphingolipids, insulin resistance, and metabolic disease: new insights from in vivo manipulation of sphingolipid metabolism. Endocr Rev 29:381-402

18. Xia M, Zhang C, Boini KM, Thacker AM, Li PL (2011) Membrane raft-lysosome redox signalling platforms in coronary endothelial dysfunction induced by adipokine visfa. Cardiovasc Res 89:401-409 